\title{
Preparation of ring crosslinked poly ( $p$-nitrile) nanoparticles and Study on adsorption behavior of uranium (VI)
}

\author{
Meixue $\mathrm{Xu}^{1,{ }^{*}, \text { Pei } \operatorname{Tian}^{1} \text {, Jing } \mathrm{Wen}^{1} \text {,Yang Yang }}{ }^{1}$,Yanfei Wang \\ ${ }^{1}$ School of chemistry and chemical engineering, University of South China , 421000, PRC
}

\begin{abstract}
Cyclo crosslinked polyphosphazenes (PPNs) were prepared by Hexachlorocyclotriphosphazene (HCCP) with unique $\mathrm{P}=\mathrm{n}$ structure and active $\mathrm{p}$-cl group and green compound phloretin. The synthesis pro cess of polyphosphazene nanospheres with Hexachlorocyclotriphosphazene as the main body and phloretin was discussed. The effects of $\mathrm{pH}$ value and solid-liquid ratio of solution on the adsorption of uranium by pol yphosphazene nanospheres were studied. The results show that polyphosphazene nanospheres are off white powder in appearance and spherical in microstructure. When the $\mathrm{pH}$ value of the solution is 4 and the solid-1 iquid ratio is $0.5 \mathrm{~g} \cdot \mathrm{L}-1$, the maximum adsorption rate of uranium is obtained.
\end{abstract}

\section{INTRODUCTION}

Adsorption method is a kind of wastewater treatment me thod that uses adsorbents with a large number of adsorpti on active groups to adsorb the radioactive substances in HLW to the surface. It is widely used in the treatment of HLW because of its advantages of simplicity, low cost a nd good effect. With the rapid development of social eco nomy, environmental protection has become one of the most concerned hot spots in today's society. Among the $\mathrm{m}$, nuclear pollution is a widely concerned environmenta 1 problem, and uranium, the main resource of nuclear fue 1 , is one of the radioactive elements in waste liquid. Ther efore, the search for a green material that can efficiently remove uranium by adsorption has a far-reaching impact on the future environmental protection. At present, diyun Chen [2] Research Group has studied the adsorption beh avior of phosphate rock for uranium (VI) in mine sewage, the adsorption capacity is $0.1133 \mathrm{mg} \cdot \mathrm{g}-1$, and the rem oval rate of uranium (VI) is $76.89 \%$. M. K. sureshkumar [3] prepared chitosan tripolyphosphate (CTPP) particles by liquid internal solid method. The adsorption capacity of CTPP particles for uranium (VI) was $236.9 \mathrm{mg} \cdot \mathrm{g}-1$. Xingcheng Ding [4] the research group prepared polyacr ylonitrile (cts-pao) grafted with amidoxime chitosan and used it to adsorb uranium (VI) from aqueous solution, wi th the removal rate of $86.02 \%$. M. H. khani [5] used the s ynthesized polypyrrole to adsorb uranium (VI) in waste water, and the adsorption capacity was about $87.72 \mathrm{mg}$

g-1. In addition, polyphosphazene microspheres have attracted the attention and application of some researche rs because of their superior characteristics to traditional a dsorption materials. However, there are few studies and 1 iterature reports on the application of polyphosphazene materials in HLW at home and abroad. In this paper, He xachlorocyclotriphosphazene co phloretin nanospheres w ere synthesized with green inorganic material Hexachlorocyclotriphosphazene as the main body and green organi c material phloretin, and characterized by SEM. Then, a series of single factor experiments were carried out to stu dy the optimal $\mathrm{pH}$ value and solid-liquid ratio of the synt hesized microspheres for uranium adsorption in aqueous solution.

\section{Experimental methods}

\subsection{Experimental process}

\subsubsection{Preparation of cyclocrosslinked Hexachlorocy clotriphosphazene co phloretin nanospheres}

Add $0.201 \mathrm{~g}$ Hexachlorocyclotriphosphazene and 0.4733 g phloretin into a $250 \mathrm{ml}$ round bottom flask, pour in 100 $\mathrm{ml}$ acetonitrile solvent, disperse and dissolve in ultraso nic $(100 \mathrm{~W})$, add $4 \mathrm{ml}$ triethylamine after dissolution, the $\mathrm{n}$ pass in nitrogen as protective gas, vacuum the flask thr ee times to remove oxygen, and react in ultrasonic (100 W) constant temperature water bath for $3 \mathrm{~h}$, The device was transferred to an oil bath at about $60{ }^{\circ} \mathrm{C}$ for $12 \mathrm{~h}$. Th e solution with the product was centrifuged to obtain soli d. Then the crude product was cross washed with ethanol and distilled water for three times, and finally dried in a $\mathrm{n}$ oven for $48 \mathrm{~h}$ to obtain crosslinked polyphosphazene $\mathrm{m}$ icrospheres. The synthesis route of cyclocrosslinked poly phosphazene phloretin nanospheres is shown in Fig. 1.

\footnotetext{
*Corresponding author: xmx_2902088301@163.com
} 


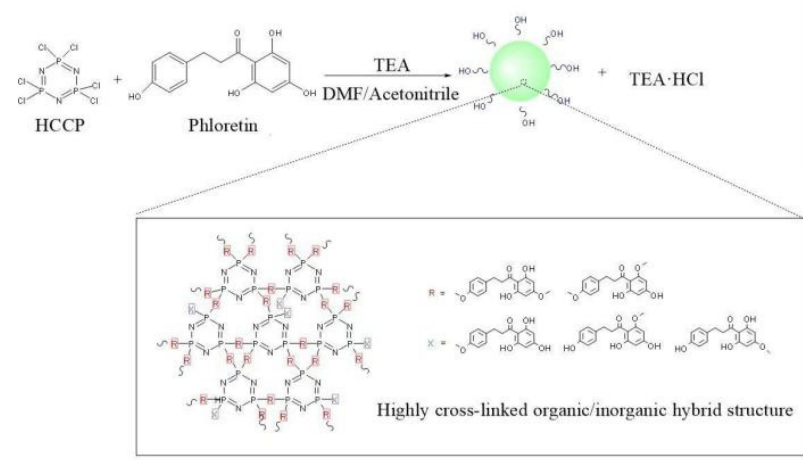

Fig. 1 Synthesis process of cyclic cross-linked polyphosphazen e-phloretin microspheres

\subsubsection{Preparation of uranium (VI) standard solution}

At first, 1g - L-1 of uranium (VI) reserve solution was prepared, and then the reserve solution was gradually dil uted to $60 \mathrm{mg} \cdot \mathrm{L}-1,50 \mathrm{mg} \cdot \mathrm{L}-1,40 \mathrm{mg} \cdot \mathrm{L}-1,30 \mathrm{~m}$ g • L-1, $20 \mathrm{mg} \cdot \mathrm{L}-1$ and $10 \mathrm{mg} \cdot \mathrm{L}-1$. Measure $1 \mathrm{ml}$ of each solution, add $1 \mathrm{ml}$ of arsenazo Tris, and prepare $\mathrm{c}$ hloroacetic acid sodium acetate buffer solution with $\mathrm{pH}$ of 2.5 to titrate the above solution to the scale line. Use $\mathrm{d}$ eionized water group as blank sample, measure three tim es in parallel on the visible spectrophotometer, record th $\mathrm{e}$ corresponding absorbance data at each concentration, a nd then use Origin Software for linear fitting, A linear cu rve and a linear fitting equation can be obtained, which is the standard curve of uranium (VI) solution.

\subsubsection{Effect of $\mathrm{pH}$ value on adsorption of uranium (V) by cyclocrosslinked polyphosphazene nanosph eres}

$10 \mathrm{ml}$ of $30 \mathrm{mg} \cdot \mathrm{L}-1$ uranium (VI) solution was accurat ely measured. The $\mathrm{pH}$ of the solution was adjusted by $\mathrm{H}$ $\mathrm{NO} 3$ and $\mathrm{NaOH}$ respectively to be 2,3.0,4.0,5.0,6.0 respe ctively. $20 \mathrm{mg}$ of HCRP co-pgm nanoparticles were adde d respectively. The reaction solution was separated by ul trafine filter membrane after the oscillation was complet ed, and $1 \mathrm{ml}$ of filtrate was transferred into $10 \mathrm{ml}$ volumet ric flask, and $1 \mathrm{ml}$ of arsenazo III $(0.05 \mathrm{wt} \%)$ reagent was added into the volumetric flask with a pipette, Then, the buffer solution of chloroacetic acid sodium acetate with $\mathrm{pH}$ of 2.5 was added to the scale line by the drop of rubb er head dropper. The absorbance of filtrate was determin ed by uv-2100 spectrophotometer. The effect of $\mathrm{pH}$ on th e adsorption of uranium (VI) by the ring crosslinked poly phosphate root skin nanomicrospheres was analyzed. Th e calculation formula of adsorption quantity (q) and rem oval rate [6].

$$
\begin{array}{r}
\mathrm{Q}\left(\mathrm{mg} \mathrm{g}^{-1}\right)=\frac{\left(\mathrm{C}_{0}-\mathrm{C}_{0}\right) \mathrm{V}}{\mathrm{m}} \\
\mathrm{R}(\%)=\frac{\left(\mathrm{C}_{0}-\underline{\mathrm{C}_{0}}\right)}{\mathrm{C}_{0}}
\end{array}
$$

Where, $\mathrm{q}$ is the adsorption capacity (mg - g-1), C0 and $\mathrm{CE}$ represent the concentration of uranium (VI) ion befor e and after adsorption (mg $-\mathrm{L}-1), \mathrm{V}$ is the volume of ur anium (VI) solution (L), and $\mathrm{M}$ is the amount of adsorbe $\mathrm{nt}(\mathrm{g})$.

\subsubsection{Effect of solid-liquid ratio on adsorption of ura nium (V) by cyclocrosslinked polyphosphazene na nospheres}

The $\mathrm{pH}$ of 30mg • L-1 uranium (VI) solution was accur ately measured, and the $\mathrm{pH}$ of the solution was adjusted $\mathrm{t}$ o $3.5 .5 \mathrm{mg}, 10 \mathrm{mg}, 15 \mathrm{mg}, 20 \mathrm{mg}, 25 \mathrm{mg}$ and $30 \mathrm{mg}$ ring cr osslinked polyphosphate nanomicrospheres were added $r$ espectively. The reaction solution was separated by ultra -fine filter membrane after the vibration was completed. $1 \mathrm{ml}$ of filtrate was transferred into $10 \mathrm{ml}$ volumetric flask, and $1 \mathrm{ml}$ of arsenazo III $(0.05 \mathrm{wt} \%)$ reagent was added in to the volumetric flask with a pipette, Then, the buffer so lution of chloroacetic acid sodium acetate with $\mathrm{pH}$ of 2.5 was added to the scale line by the drop of rubber head dr opper. The absorbance of filtrate was determined by uv2100 spectrophotometer. The effect of solid-liquid ratio on the adsorption of uranium (VI) by the ring crosslinked polyphosphate root skin nanosphere was analyzed.

\section{Results and discussion}

\subsection{Characterization of cyclocrosslinked Hexachloroc yclotriphosphazene co phloretin nanospheres by SE M-EDS}

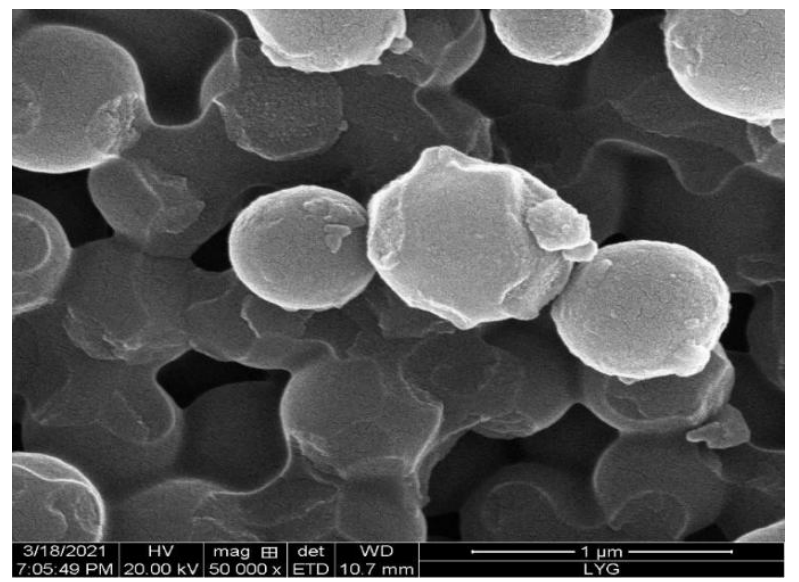

Fig.2 Scanning electron microscopic study of pre adsorption ri ng crosslinked polyphosphazene phloretin nanospheres 


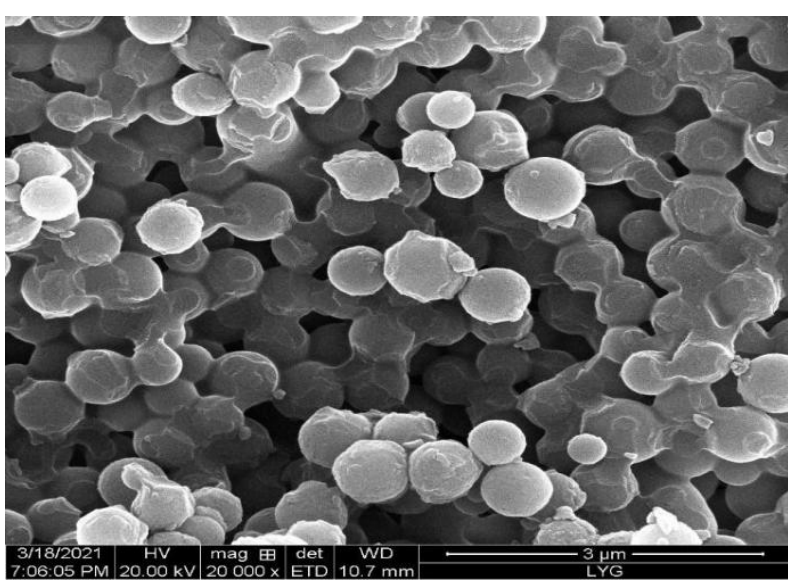

Fig.3 Scanning electron microscopic study of pre adsorption ri ng crosslinked polyphosphazene phloretin nanospheres

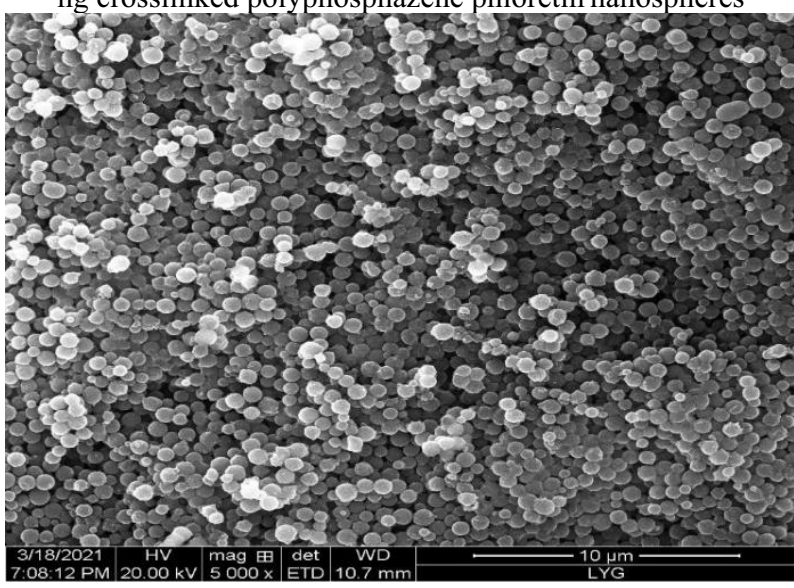

Fig.4 Scanning electron microscopic study of pre adsorption ri ng crosslinked polyphosphazene phloretin nanospheres

It can be seen from figures 2, 3 and 4 that the material pr esents regular and uniform spherical shape, which is in li ne with the initial conjecture on the structure of cyclocro sslinked Hexachlorocyclotriphosphazene co phloretin na nospheres.

\subsection{Establishment of standard curve of uranium (VI) solution}

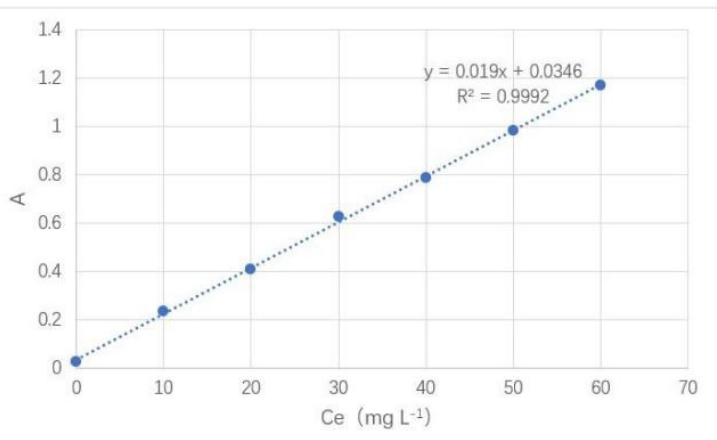

Fig.5 Uranium standard curve

It can be seen from figure 5 that in the range of 10 $60 \mathrm{mg} \cdot \mathrm{L}-1$, there is a good linear relationship between the concentration of uranium (VI) and its absorbance (R2 $=0.9992$ ), and the line ar equation can be obtained, as shown in formula 2.1
$\mathrm{A}=0.019 \mathrm{Ce}+0.0346$

Where $\mathrm{a}$ is the absorbance of uranium (VI) and $\mathrm{Ce}$ (mg $\mathrm{L}-1$ ) is the concentration of uranium (VI). When the absorbance of unknown uranium (VI) solution is known, the fitted equation can be used to calculate its concentrat ion.

\subsection{Effect of $\mathrm{pH}$ value on adsorption of uranium (VI) by cyclophosphazene nanoparticles}

One of the key factors for the adsorption of uranium (VI) by the cyclocrosslinked $\mathrm{HCH}$ co-pgm nanoparticles is the $\mathrm{pH}$ value in the wastewater containing uranium, which has a great influence on the adsorption behavior. The $\mathrm{pH}$ value not only affects the binding sites on the adsorbent surface, but also affects the morphology of the adsorbate in the solution [1]. The relationship between the $\mathrm{pH}$ valu e of solution and the adsorption amount of uranium (VI) is shown in Figure 6, which has an effect on the adsorpti on of uranium (VI) by microspheres. It can be seen from the figure that when the $\mathrm{pH}$ is less than 2.0, the correspo nding adsorption amount is zero, indicating that when the $\mathrm{pH}$ is lower than 2.0, the microspheres have no adsorpt ion effect on uranium containing wastewater. When the $\mathrm{pH}$ is less than 4 and greater than 2, the adsorption amou nt increases with the increase of $\mathrm{pH}$ value, The adsorptio $\mathrm{n}$ capacity of $\mathrm{U}(\mathrm{VI})$ by the cyclocrosslinked ppn-pgms $\mathrm{i}$ ncreases gradually. The above phenomena may be due to the presence of a large amount of hydrogen ions in urani um solution under acidic conditions, which may be easie $r$ to bind with the adsorption sites in the cyclocrosslinked ppn-gpm nanoparticles, which leads to the particle of th e microspheres, which is due to the repelling of the same

-sex charge, The particles will repel the positively charge d uranium (VI) ions, which is not conducive to the adsor ption of uranium (VI) [7] in the solution of the microsph eres, so this trend is presented. When the $\mathrm{pH}$ value of the solution is 4 , the content of hydrogen ion in the solution decreases gradually. At this time, a large number of activ e adsorption sites are preferentially combined with urani um (VI) ions with positive charge, thus obtaining the ma ximum adsorption capacity. However, it can be seen fro $m$ the figure that the adsorption of uranium by the micros pheres will decrease when the $\mathrm{pH}$ of the solution continu es to increase and is greater than 4. It is possible that ura nium (VI) is easy to hydrolyze in this $\mathrm{pH}$ range, and even form (UO2) $3(\mathrm{OH})-7$ with negative charge. The appea rance of such ions may produce repulsion with the surfac e of the ring crosslinked hch-co-gpn nanoparticles, whic $h$ also leads to the decrease of the adsorption strength of the adsorbent. Therefore, when the $\mathrm{pH}$ value of the soluti on is 4 , the adsorption behavior of the cyclocrosslinked $\mathrm{p}$ pn-gpm nanoparticles to uranium (VI) is the best. At this time, the best adsorption capacity is $39.33 \mathrm{mg} \cdot \mathrm{g}-1$, and the removal rate reaches $65.86 \%$. 


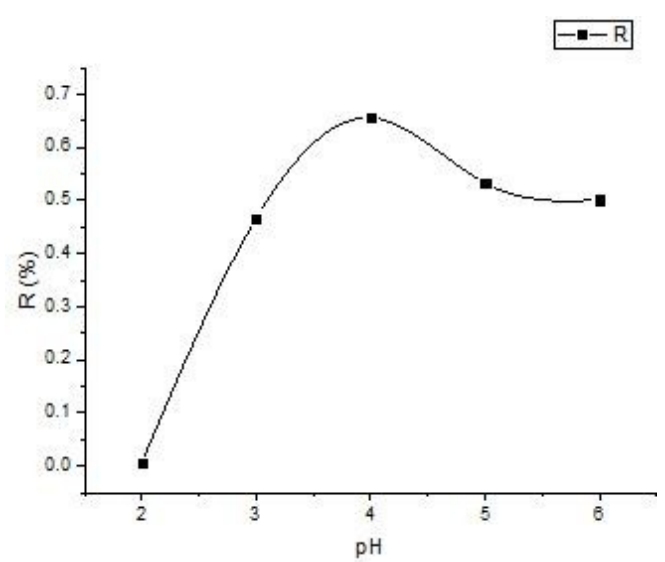

Fig.6 The effect of $\mathrm{pH}$ on adsorption of uranium

\subsection{Effect of solid-liquid ratio on adsorption of urani um (VI) by cyclocrosslinked Hexachlorocyclotriphosp hazene co phloretin nanospheres}

The ratio of solid to liquid affects the economic benefit o $f$ adsorption behavior. Too high or too low ratio of solid $t$ $\mathrm{o}$ liquid is unfavorable to adsorption behavior. For this $\mathrm{e}$ xperiment, when the solid-liquid ratio is too large, not on ly the excess adsorbent will be wasted, but also the adsor ption capacity will be reduced [8], and the removal rate will not increase significantly, or even decline. When the solid-liquid ratio is low, the adsorption rate of the adsor bent for uranium (VI) will slow down, and even can not absorb the remaining uranium (VI) ions in the solution. I $\mathrm{n}$ order to study the effect of solid-liquid ratio on the ads orption of uranium (VI) by cyclohexachlorocyclotriphos phazene co phloretin nanospheres, the initial concentrati on of uranium (VI) was $3 \mathrm{G} \cdot \mathrm{L}-1$, the adsorption time was $2 \mathrm{~h}$, and the $\mathrm{pH}$ value was adjusted to 4.0. The volu me of uranium (VI) solution was $10 \mathrm{ml}$, and the mass of adsorbent was 4-8 $\mathrm{mg}$. It can be seen from the influence of solid-liquid ratio on adsorption of uranium (VI) by mi crospheres in Fig. 7 that with the increase of solid-liquid ratio $(\mathrm{M} / \mathrm{V})$, the removal rate of uranium (VI) by cycloh exachlorocyclotriphosphazene co phloretin nanospheres gradually increases, and when the solid-liquid ratio is gre ater than $0.54 \mathrm{~g} \cdot \mathrm{L}-1$, it gradually tends to be flat, and $\mathrm{i}$ $\mathrm{n}$ a slight decline, the removal rate is $62.13 \%$. This may be due to the existence of a certain "shielding effect [9]" on the surface of the adsorbent after reaching a certain ad sorption capacity, which has a certain repulsive effect on the remaining uranium (VI) ions. At this time, due to the decrease of the concentration of uranium (VI) ions, ther $\mathrm{e}$ is not enough driving force to offset the repulsive force. Therefore, after the concentration of $0.54 \mathrm{~g} \cdot \mathrm{L}-1$, the $\mathrm{r}$ emoval rate gradually decreased. It is speculated that the best removal rate is $62.13 \%$ when the solid-liquid ratio is $0.54 \mathrm{~g} \cdot \mathrm{L}-1$.

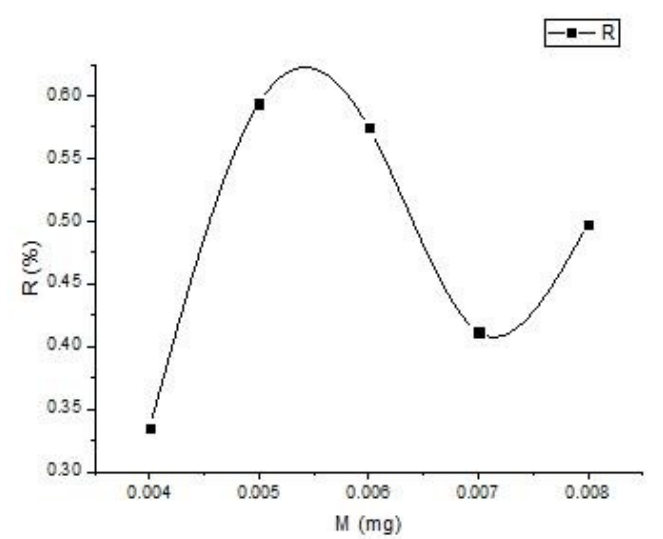

Fig.7 The effect of solid-to-liquid ratio on adsorption of uraniu

\section{Conclusion}

In this study, a novel adsorbent, cyclocrosslinked Hexac hlorocyclotriphosphazene co phloretin nanospheres, was synthesized and characterized by SEM. A series of singl e factor experiments were carried out to study the adsorp tion conditions of the synthesized microspheres for urani um in aqueous solution. The results showed that when th e solution $\mathrm{pH}$ value was 4 and the solid-liquid ratio was $0.5 \mathrm{~g} \cdot \mathrm{L}-1$, the adsorption behavior of cyclophosphazene phloretin nanospheres for uranium (VI) was the best.

\section{References}

1. Fu Ying Yi, Ding Xin Geng, Dou Tian Jun, et al. Ap plication of adsorption technology in HLW [J]. Mate rials guide, 2013, 27 (2): 255-258

2. Chen B, Jin W, Kong L, et al. Adsorption of uraniu $\mathrm{m}$ from uranium mine contaminated water using pho sphate rock apatite (PRA): Isotherm, kinetic and cha racterization studies $[\mathrm{J}]$. Colloids \&amp; Surfaces A Physicochemical \&amp; Engineering Aspects, 2017, 520:612-621.

3. Sureshkumar M K, Das D, Mallia M B, et al. Adsor ption of uranium from aqueous solution using chitos an-tripolyphosphate (CTPP) beads [J]. Journal of Ha zardous Materials, 2010, 184(1): 65-72.

4. Xu C, Wang J, Yang T, et al. Adsorption of uranium by amidoximated chitosan-grafted polyacrylonitrile, using response surface methodology [J]. Carbohydr ate Polymers, 2015, 121:79-85.

5. Abdi S, Nasiri M, Mesbahi A, et al. Investigation of Uranium (VI) Adsorption by Polypyrrole [J]. Journa 1 of Hazardous Materials, 2017, 332: 132-139.

6. Ghalami Z, Ghoulipour V, Khanchi A. Hydrogen an d deuterium adsorption on uranium decorated graph ene nanosheets: A combined molecular dynamics an $d$ density functional theory study [J]. Current Applie d Physics, 2019, 19(4): 536-541.

7. Huynh J, Palacio R, Safizadeh F, et al. Adsorpt ion of Uranium over NH2-Functionalized Ordered Silica in Aqueous Solutions [J]. Acs Appl Mater Int erfaces, 2018,22:35-38. 